- the cause of considerable anxiety in certain types of construction-is also under examination.

On the subject of damage to buildings by vibration from traffic, machinery, pile-driving and other sources, the investigations, started some years ago and discontinued, are now being resumed, and a preliminary programme of research has been outlined. While it would appear from the report that vibration stresses are, in general, below the estimated fatigue strength of brickwork and concrete even after allowing for considerable stress amplification due to resonance, they are, however, above the compressive fatigue strength of lime mortar, which is therefore liable to gradual disintegration. For the more thorough investigation of this most complex question, special vibrators are being designed for use both on the structures and on the ground, and dynamic extensometers are to be used in the measurement of strains.

The determination of Young's modulus for various building materials, including stone, brick, concrete tiles and asbestos sheeting, has been effected by measuring the frequency of vibration of a specimen in a special apparatus which is described. The error in the observed value of the frequency can be limited to \pm 0.5 per cent, and the modulus is derived from the formula $E=4 l^{2} n^{2} p$.

Wind-pressure measurements made on the Severn Bridge during a gale in January are discussed, and further tests on the shielding effect of one building on another have yielded certain general conclusions. To carry this investigation further, a model of a portion of London is being made for tests in a wind tunnel.

The general research work of the Station has included the important problem of the weathering qualities of natural building stones, and the report claims that by applying simple tests the value of Portland stone samples can now be determined with confidence. Certain common terms in specifications are held to be needlessly restrictive of choice and tend to exclude material of the best weathering quality. The information available points to the prime importance of careful selection of the stone, and suggests considerable doubt as to the value of preservatives. The effects of atmospheric pollution and of various physical factors influencing weathering are also discussed, and a lengthy investigation on the relation of micro-organisms to the decay of stone is stated to have shown that these are not directly responsible in any considerable degree for the processes of decay-nor, as yet, have they boen found to exert any indirect influence. Many other building materials have been under review, and the notes on these give valuable information as to their properties.

It is, however, with structures and the strength of materials that the major part of the report deals, and in this section the results of the investigations are set out in detail. Concrete beams, piles and road slabs have been the subjects of large-scale experiments, and in the case of beams comparative tests were made for the Ministry of Transport to ascertain the behaviour under load of ordinary reinforced concrete, of Ritchie type and of modified Ritchie type continuous girders. Photographs, diagrams and tables give a clear picture of the results obtained, and these show that the ultimate loads carried by the Ritchie and modified Ritchie beams are about 15 per cent higher than those carried by the ordinary type. If, however, the point of failure be taken as that at which the rate of increase of deflection with load begins to become excessive, the conclusion is that there is little to choose between the three types, which each carry, at this point, about three times the working load.

From these brief notes of the subject matter of the report, it will be gathered that this is a volume which should receive close attention from those who are engaged in research in this or cognate fields, or associated professionally or industrially with modern problems of building.

J. A. C.

\title{
Increasing Aridity in West Africa
}

$\mathrm{B}^{\mathrm{E}}$ EFORE Section E (Geography) of the British Association moeting at Norwich, Prof. E. P. Stebbing returned to the subject of "The Encroaching Sahara", on which he read a very important paper to the Royal Geographical Society in March of this year (see Geog. J., 85, 506, June 1935). Leaving on one side the difficult and still disputed question of secular desiccation, it is clear that the activities of man have resulted in assisting the spread of desert and semidesert conditions-" "the eastern Sahara Desert is advancing south and threatening the future prosperity of considerable stretches of West Africa".

As a forester, Prof. Stebbing naturally attributes this to the removal of forest, but it would be nearer the truth to say that the removal of any natural vegetation cover, whether by man-made fire and the plough or through grazing by man's domestic animals, conduces to soil erosion and so to deterioration and apparent desiccation. This has happened in the middle western States of America through the ploughing of prairie grassland, and is now being actively combatted; it is happening in West Africa through the shifting cultivation and increasing herds of a semi-civilised population, and is not yet being arrested.

Prof. Stebbing's suggestion for West Africa is to preserve against human occupation and grazing two continuous east to west belts of forest-one, with a minimum width of $7 \frac{1}{2}$ miles, of dry forest in the latitude of Lake Chad; the other a belt 30-50 miles wide in the moister savannah forests farther south. It is not a question of planting forest belts as has been suggested for the United States, but is one of preserving strips of the natural vegetation.

Such a suggestion seems simple, but it is directly opposed to British Government policy in West Africa. The laudable aim of the British has been to interfere as little as possible with the habits of the people, and so shifting cultivation and indiscriminate grazing are permissible. Indeed, under the peaceful conditions of the British regime the people, their herds and flocks have all multiplied, and the evil has been intensified at an ever-increasing pace. It is essential that the state of affairs should be widely known amongst those concerned with education in West Africa-part of the remedy lies in their hands.
L. D. S. 